\title{
sciendo
}

\section{STUDY ON GROWTH ENHANCEMENT AND THE PROTECTIVE EFFECTS OF DIETARY PREBIOTIC INULIN ON IMMUNITY RESPONSES OF RAINBOW TROUT (ONCORHYNCHUS MYKISS) FRY INFECTED WITH AEROMONAS HYDROPHILA}

\author{
Hamed Ghafarifarsani ${ }^{1}$, Ghasem Rashidian ${ }^{2}$, Tahereh Bagheri ${ }^{3}$, Seyed Hossein Hoseinifar ${ }^{4}$,
} Hien Van Doan ${ }^{5 *}$

\author{
${ }^{1}$ Department of Fisheries, Ph.D. Candidate in Fisheries, Faculty of Agriculture and Natural Resources, \\ Urmia University, Urmia, Iran \\ ${ }^{2}$ Aquaculture Department, Ph.D. Candidate in Fisheries, Faculty of Marine Sciences, \\ Tarbiat Modares University, Noor, Iran \\ ${ }^{3}$ Offshore Fisheries Research Center, Agricultural Research Education and Extension Organization \\ (AREEO), Iranian Fisheries Sciences Research Institute, Chabahar, Iran \\ ${ }^{4}$ Department of Fisheries, Faculty of Fisheries and Environmental Sciences, Gorgan University \\ of Agricultural Sciences and Natural Resources, Gorgan, Iran \\ ${ }^{5}$ Department of Animal and Aquatic Sciences, Faculty of Agriculture, Chiang Mai University, \\ Chiang Mai 50200, Thailand \\ •Corresponding author: hien.d@cmu.ac.th
}

\begin{abstract}
The present study evaluated the effects of dietary inulin on growth performance, body composition, serum, biochemical, and mucus immune factors; as well as innate immune responses of rainbow trout fry challenged with Aeromonas hydrophila. Four diets were prepared using a commercially available fish feed as a basal diet and different levels of prebiotic inulin incorporation; 0 (control), 1, 2, and 3\%; referred to as C, T1, T2, and T3, respectively. The findings of the 60-day feeding trial showed that inulin inclusion affected final weight, food conversion rate (FCR), and specific growth rate (SGR) compared to that of the control group $(\mathrm{P}<0.05)$, in which the lowest FCR was observed in T3. Body composition analysis revealed that inulin significantly increased protein content and decreased lipid levels, especially in the $\mathrm{T} 1$ and $\mathrm{T} 2$ groups. The lowest ash level was noticed in T2 $(\mathrm{P}<0.05)$. Blood total protein, albumin, globulin, cholesterol, and glucose were not affected by inulin supplementation $(\mathrm{P}>0.05)$. Analysis of humoral immune responses showed that the inulin supplements significantly increased lysozyme and complement activities $(\mathrm{P}<0.05)$, as well as causing higher red blood cell count $(\mathrm{RBC})$ and hemoglobin $(\mathrm{Hb})$ in fish fed $2 \%$ inulin, while no significant differences were observed among other treatments $(P>0.05)$. The mucosal parameters, including lysozyme; alkaline phosphatase (excluding ACH50); protease activities; and total immunoglobulin (IgM) improved significantly $(\mathrm{P}<0.05)$, particularly in the T2 group. The T2 group also demonstrated the highest survival rate among all groups. The present findings indicate that dietary administration of inulin promotes growth and biochemical parameters, as well as serum immunity and mucosal immune responses of rainbow trout, in which a $2 \%$ inclusion produced the best results.
\end{abstract}

Key words: prebiotic, growth indices, immunity, skin mucus, rainbow trout, Aeromonas hydrophila 
Rainbow trout (Oncorhynchus mykiss) is an economically important species for aquaculture in many countries (FAO, 2018). It is widely cultured in Iran under intensive or semi-intensive systems and a suitable species for cage culture in brackish waters. However, intensification of culture systems leads to stress and causes infectious diseases in trout farming, which accounts for a significant decrease in production levels in local farms (North et al., 2006; Sahin et al., 2014; Mirghaed et al., 2018; Hoseini et al., 2020). Aeromonas hydrophila is a major bacterial pathogen, which causes dermal ulceration and hemorrhagic septicemia in many fish species (Nya and Austin, 2009; Zargari et al., 2018; Hoseini et al., 2020). However, the use of antibiotics for disease prevention and fish growth enhancement results in negative effects upon consumer safety, as well as producing antibiotic residues which increase the regulatory restrictions on the antibiotics' utilization (Cabello, 2006; Sørum, 2006). Moreover, emerging antibiotic-resistant strains of $A$. hydrophila have been reported in fish farms (Sørum, 2006). As the innate immune system in fish is vital in the response to primary stressors, as well as infectious diseases, the enhancement of innate immune responses, disease resistance, and subsequent improvement in health are of growing interest to researchers (Song et al., 2014; Yan et al., 2017; FAO, 2018). Immunostimulants present a promising approach to prevent and/or control diseases in aquaculture (Chakraborty and Hancz, 2011; Hoseinifar et al., 2015; FAO, 2018; Hoseini et al., 2019). Prebiotics have recently attracted extensive attention in aquaculture (Ringø et al., 2010), as non-digestible food ingredients that are metabolized through gut microbiota (Ringø et al., 2013). They provide a beneficial influence on the host animal's health through selective growth inducement, metabolizing healthinducing bacteria in the intestinal tract, and/or improving the host's intestinal balance (Manning and Gibson, 2004; Kelly, 2009).

Fructooligosaccharides (FOS), transgalactooligosaccharides (TOS), mannan oligo-saccharides (MOS), lactose, and inulin are well-known and often used prebiotics (Teitelbaum and Walker, 2002; Huebner et al., 2007; Kelly, 2009; Hoseinifar et al., 2015). Inulin and its derivatives, contain linear chains of fructose, known as fructans (Madrigal and Sangronis, 2007), and are abundant in several plant species. Several studies have reported inulin's involvement in the digestion, absorption, and metabolism of various nutrients in terrestrial organisms (Teitelbaum and Walker, 2002; Huebner et al., 2007); as well as the beneficial effects on aquatic animal growth and innate immune responses (Ibrahem et al., 2010; Sheikholeslami Amiri et al., 2012; Attia et al., 2015; Syed Raffic et al., 2016). However, contrasting results have also been reported on the dietary effects of inulin on growth, immunity, and survival rates in different fish species; suggesting the species-dependent characteristics of the prebiotic, as observed in Nile tilapia (Oreochromis niloticus) (Ibrahem et al., 2010), Caspian roach (Rutilus rutilus caspicus) (Khosravi et al., 2010; Soleimani et al., 2012), common carp (Cyprinus carpio) (Akrami et al., 2012; Ebrahimi et al., 2012; Amirkolaie and Rostami, 2015; Eshaghzadeh et al., 2015), rainbow trout (Oncorhynchus mykiss) (Staykov et al., 2007; Akrami et al., 2009 a; Sheikholeslami Amiri et al., 2012; Amirkolaie et al., 2013; Yarahmadi et al., 2014 a, b; Yarahmadi et al., 2016; Khodadadi et al., 2018), beluga (Huso huso) (Akrami et al., 2009 b; Akrami et al., 2011; Ahmadifar et al., 2011), turbot larvae (Mahious et al., 2006), stellate stur- 
geon (Akrami et al., 2013), juvenile white shrimp (Zhou et al., 2007; Li et al., 2009; Yousefian and Amiri, 2009), hybrid striped bass (Burr et al., 2010), Rachycentron canadum (Salze et al., 2008), Penaeus semisulcatus (Genc et al., 2007 a), hybrid tilapia (Genc et al., 2007 b; Ibrahem et al., 2010), European sea bass (Torrecillas et al., 2007), and salmon (Grisdale-Helland et al., 2008).

While previous studies on inulin have focused on the improvements of growth performance and general health conditions (Sheikholeslami Amiri et al., 2012), little information is available on the effects of inulin on the blood biochemical parameters, or humoral and mucosal immune responses in rainbow trout. The present study, therefore, was conducted to assess the effects of dietary inulin on growth performance, body composition, and innate immune responses; as well as the hematology, biochemical, and skin mucosal responses of rainbow trout after infection with A. hydrophila.

\section{Material and methods}

\section{Fish rearing and experimental design}

Rainbow trout fingerlings were purchased from a private local fish farm in Karaj, Iran; and transferred to the laboratory. After acclimatization to laboratory conditions for two weeks; fish, with an average weight: $20.57 \pm 0.87 \mathrm{~g}$, were randomly selected and placed in twelve circular $300 \mathrm{~L}$ fiberglass-reinforced plastic (FRP) tanks, maintained with continuous water supply at a rate of approximately $2-3 \mathrm{~L} \mathrm{~min}^{-1}$ with constant aeration via air stones connected to a central air compressor. The experimental diets were conducted in triplicate with ten fish each. Fish were fed 3\% of their respective biomass, three times a day, for 60 days, following Yarahmadi et al. (2016). Water quality parameters, measured daily with a portable multi-meter (HACH, USA), included temperature, dissolved oxygen, and $\mathrm{pH}$, maintained at $15.38 \pm 0.75^{\circ} \mathrm{C}, 8.28 \pm 0.74 \mathrm{mg} \mathrm{L}^{-1}$, and $7.18 \pm 0.42$, respectively.

\section{Experimental diets}

A commercial diet (FFT2, Faradaneh.co) containing 44\% crude protein, 14\% crude lipid, $8 \%$ moisture, $10 \%$ ash, and $1 \%$ phosphorous was used as the basal diet. The commercially available prebiotic Inulin Orafti ${ }^{\circledR}$ GR (Beneo Company, Belgium) was suspended in codfish oil, and incorporated into the basal diet at $0 \%$ (control, $\mathrm{C}$ ), $2 \%$ (T2), and $3 \%$ (T3); and stored at $-20^{\circ} \mathrm{C}$ until used.

\section{Sampling}

After the trial, feeding ceased for 24 hours. Nine fish from each treatment were then randomly removed and anesthetized with clove powder $(200 \mathrm{ppm})$ in preparation for blood and mucus sampling. Blood samples were divided into two parts, transferred into $2.5 \mathrm{ml}$ heparinized syringes and non-heparinized syringes, respectively, stored without anticoagulant overnight at $4{ }^{\circ} \mathrm{C}$, then centrifuged at $3500 \mathrm{rpm}$ for ten minutes. The serum was collected and kept at $-80^{\circ} \mathrm{C}$ for biochemical and im- 
munological parameter assay. Blood samples within the heparinized syringes were used to assay the hematological parameters.

Nine fish were also collected from each treatment for skin mucus collection. Specimens were dipped in water for the collection of higher sample volumes and deposited in polyethylene bags containing $10 \mathrm{ml}$ of $50 \mathrm{mM} \mathrm{NaCl}$, according to the practice of Ross et al. (2000). The bags were gently shaken by hand for approximately two minutes, and the mucus samples were transferred to $15 \mathrm{ml}$ sterile tubes and centrifuged at $1500 \mathrm{~g}\left(4^{\circ} \mathrm{C}\right)$ for ten minutes. The supernatant was then stored at $-80^{\circ} \mathrm{C}$ for further analysis. The whole-fish body was analyzed for moisture, crude protein, crude lipid, and ash contents according to the standard methods of the AOAC (2019). Moisture was determined by drying the samples at $105^{\circ} \mathrm{C}$ for 24 hours to determine ash content and incinerated at $550^{\circ} \mathrm{C}$, the protein was measured via the Kjeldahl method, and total lipids were measured using the Soxhlet method.

\section{Growth performance}

At the end of the 60-day feeding trial, growth performances of all fish were calculated through the following formulas (Khodadadi et al., 2018):

Feed conversion rate $(\mathrm{FCR})=$ total feed given $(\mathrm{g}) /$ weight gain $(\mathrm{g})$ Specific growth rate $(\mathrm{SGR})\left(\% \mathrm{~d}^{-1}\right)=(\{\ln$ final wt $(\mathrm{g})-\ln$ initial wt $(\mathrm{g})\} /$ days $) \times$ $\times 100$

Survival rate $(\mathrm{SR})(\%)=($ final numbers $/$ initial numbers $) \times 100$

\section{Hematological parameters}

Heparinized blood was diluted in PBS to quantify white blood cells (WBC) and red blood cells (RBC) using a hemocytometer slide (Sarder et al., 2001). Average red blood cell volume (MCV), mean red blood cell hemoglobin $(\mathrm{MCH})$, and mean blood concentration of hemoglobin (MCHC) parameters in the red blood cells were measured through the following equations (Benfey and Sutterlin, 1984):

$\mathrm{MCHC}=\mathrm{Hb} \times 10 / \mathrm{Hct}$

$\mathrm{MCV}=$ Het $\times 10 / \mathrm{RBC}($ million $)$

$\mathrm{MCH}=\mathrm{Hb} \times 10 / \mathrm{RBC}$ (million)

Hematocrit (Hct) was determined by the microhematocrit method, as described by Brown (1988), and reported as the percentage of packed cell volume. Optical Density (OD) factor of the solution was measured using semi-automatic spectrophotometry at $540 \mathrm{~nm}$, and compared to the standard curve, to determine hemoglobin $(\mathrm{g} /$ dl) levels, based on the cyanohaemoglobin method (Larsen, 1964).

\section{Biochemical parameters}

Commercial kits (Pars Azmun Co., Tehran, Iran) were used to estimate the total serum protein, albumin, glucose, triglyceride, cholesterol, and cortisol levels of the fish serum according to Yarahmadi et al., 2016. All biochemical parameters were measured using an automatic biochemical analyzer (Roche Hitachi 911 Chemistry Analyzer, Tokyo, Japan). 


\section{Immunological parameters}

Serum lysozyme activity, determined according to Parry et al. (1965), was measured in terms of the susceptibility of the characterized gram-positive bacteria Micrococcus lysodeikticus (Sigma, USA). The micro-protein determination method was employed to quantifying serum total immunoglobulin levels (total Ig) (C-690; Sigma). A $12 \%$ polyethylene glycol solution was applied to measure the precipitation and total Ig levels. Protein contents were estimated both before and after precipitation (Siwicki and Anderson, 2000). Alternative complement activity (ACH50) was determined, based on sheep red blood cell (SRBC) hemolysis (Ortuno et al., 1998). $\mathrm{ACH} 50$ represents the volume of serum yielding 50\% hemolysis and is expressed in units per $\mathrm{ml}$.

\section{Mucosal immunological indicators}

Similarly, skin mucus immune parameters, including total Ig, lysozyme, and ACH50 activities were also determined in the serum samples. Skin mucus protease activity was measured via the azocasein hydrolysis method described by Ross et al. (2000), with minor modifications. The activity of alkaline phosphatase (ALP) in the mucus was measured using a commercial kit (Pars Azmun Co., Tehran, Iran).

\section{Aeromonas hydrophila challenge test}

After the 60-day feeding trial, 30 fish were removed from each treatment and anesthetized with clove powder $(200 \mathrm{ppm})$. The specimens were then challenged with intraperitoneal injection: $0.05 \mathrm{ml}$ of bacterial suspension [A. hydrophila (AH04), containing $1 \times 10^{8} \mathrm{CFUs}$ mixed with $100 \mu \mathrm{L}$ of PBS] per fish. Yarahmadi et al. (2016) suggested that this concentration may be indicative of the $\mathrm{LD}_{50}$ properties of the A. hydrophila strain. Survival rates were calculated after two weeks (Farsani et al., 2019).

\section{Statistical analysis}

Initially, normality and homogeneity of variance were checked via KolmogorovSmirnov, and all data were represented as mean \pm standard deviation, and analyzed using SPSS software, Version no. 24.00 (SPSS Inc., Chicago, IL, USA). Differences of treatments determined through one-way analysis of variance (ANOVA) followed Duncan's multiple range tests, in which $\mathrm{P}$ values less than 0.05 were considered statistically significant.

\section{Results}

\section{Growth performance}

The growth performances of rainbow trout fed with inulin-supplemented diets are presented in Table 1. The results determined that the T2 treatment had the highest values for FW, WG, and SGR, as well as the lowest FCR of all groups $(\mathrm{P}<0.05)$. Survival rates were high, between 85 and $96 \%$, and most significant in the $1 \%$ and $2 \%$ inulin inclusions $(\mathrm{P}<0.05$; Table 1$)$. 
Table 1. Growth performance of rainbow trout fed with dietary inulin at different levels for 60 days

\begin{tabular}{l|rr|r|r}
\multicolumn{5}{c}{$(\mathrm{n}=30)$} \\
\hline \multicolumn{1}{c}{ Parameters } & Control & \multicolumn{1}{c}{$\mathrm{T} 1$} & \multicolumn{1}{c}{$\mathrm{T} 2$} & \multicolumn{1}{c}{$\mathrm{T} 3$} \\
\hline Initial weight (g) & $20.67 \pm 0.17$ & $20.84 \pm 0.22$ & $20.34 \pm 0.43$ & $20.42 \pm 0.24$ \\
Final weight (g) & $50.52 \pm 0.45 \mathrm{~d}$ & $59.35 \pm 0.03 \mathrm{~b}$ & $63.5 \pm 0.22 \mathrm{a}$ & $54.26 \pm 0.09 \mathrm{c}$ \\
Weight gain (g) & $29.85 \pm 0.22 \mathrm{~d}$ & $38.51 \pm 0.25 \mathrm{~b}$ & $43.15 \pm 0.65 \mathrm{a}$ & $33.84 \pm 0.15 \mathrm{c}$ \\
FCR & $1.65 \pm 0.03 \mathrm{a}$ & $1.31 \pm 0.03 \mathrm{c}$ & $1.21 \pm 0.03 \mathrm{~d}$ & $1.43 \pm 0.05 \mathrm{~b}$ \\
SGR (\%/d) & $1.48 \pm 0.01 \mathrm{~d}$ & $1.74 \pm 0.01 \mathrm{~b}$ & $1.89 \pm 0.04 \mathrm{a}$ & $1.62 \pm 0.01 \mathrm{c}$ \\
SR (\%) & $85.33 \pm 1.52 \mathrm{c}$ & $95.66 \pm 0.57 \mathrm{a}$ & $96.00 \pm 1.00 \mathrm{a}$ & $92.66 \pm 1.52 \mathrm{~b}$ \\
\hline
\end{tabular}

WG: weight gain; SGR: specific growth rate; FCR: feed conversion ratio; SR: survival rate.

Data represented as mean $\pm \mathrm{SD}$. Different letters $(\mathrm{a}-\mathrm{c})$ in the same row indicate significant differences $(\mathrm{P}<0.05)$.

\section{Fish body composition}

The specimens' proximate body compositions are shown in Table 2. Moisture analyses indicated a significantly different level among all treatments, the lowest of which was found in the T1 treatment. Protein contents revealed significant increases in fish fed 1 and $2 \%$ dietary inulin inclusions over both the $3 \%$ inclusion and the control diet. The T1 and T2 inulin groups also presented significantly higher lipid contents compared to fish fed $3 \%$ inulin and the control $(\mathrm{P}<0.05)$. Significant decreases were also observed in the fish fed inulin (1 and $2 \%$ ) compared to the control $\operatorname{diet}(\mathrm{P}<0.05)$.

Table 2. Body compositions of rainbow trout fed dietary inulin at different levels for 60 days $(\mathrm{n}=30)$

\begin{tabular}{l|c|c|c|c}
\hline \multicolumn{1}{c|}{ Parameters (\%) } & Control & T1 & T2 & T3 \\
\hline Moisture & $71.55 \pm 0.09 \mathrm{a}$ & $70.25 \pm 0.14 \mathrm{~d}$ & $70.65 \pm 0.15 \mathrm{c}$ & $71.22 \pm 0.12 \mathrm{~b}$ \\
Crude protein & $14.51 \pm 0.2 \mathrm{~b}$ & $15.29 \pm 0.16 \mathrm{a}$ & $15.31 \pm 0.18 \mathrm{a}$ & $14.81 \pm 0.13 \mathrm{~b}$ \\
Crude lipid & $8.58 \pm 0.11 \mathrm{a}$ & $7.92 \pm 0.07 \mathrm{c}$ & $7.77 \pm 0.09 \mathrm{c}$ & $8.17 \pm 0.07 \mathrm{~b}$ \\
Ash & $4.26 \pm 0.14 \mathrm{a}$ & $3.85 \pm 0.15 \mathrm{~b}$ & $3.46 \pm 0.12 \mathrm{c}$ & $4.16 \pm 0.04 \mathrm{a}$ \\
\hline
\end{tabular}

Data represented as mean $\pm \mathrm{SD}$. Different letters $(\mathrm{a}-\mathrm{c})$ in the same row indicate significant differences $(\mathrm{P}<0.05)$.

\section{Hematological indices}

Hematological indices, including $\mathrm{MCHC}, \mathrm{MCH}, \mathrm{MCV}, \mathrm{RBC}, \mathrm{WBC}$, Hct, and $\mathrm{Hb}$, are presented in Table 3. Except for $\mathrm{RBC}$ and $\mathrm{Hb}$, there were no significant differences among treatments. $\mathrm{RBC}$ and $\mathrm{Hb}$ were significantly higher in treatments with $2 \%$ inulin $(\mathrm{P}<0.05)$.

\section{Biochemical and innate immune responses}

Throughout the 60-day experiment, triglyceride changed significantly compared to the control $(\mathrm{P}<0.05)$. Cortisol significantly increased in the $\mathrm{T} 2$ group compared to the control group $(\mathrm{P}>0.05)$, yet no significant difference was found among the other treatments $(\mathrm{P}<0.05$; Table 4$)$. 
Table 3. Hematology performance of rainbow trout fed different levels of dietary inulin for 60 days

\begin{tabular}{l|ccccc}
\multicolumn{5}{c}{$(\mathrm{n}=30)$} \\
\hline \multicolumn{1}{c}{ Parameters } & Control & $\mathrm{T} 1$ & $\mathrm{~T} 2$ & $\mathrm{~T} 3$ \\
\hline $\mathrm{RBC}\left(\times 10^{6} / \mu \mathrm{l}\right)$ & $1.21 \pm 0.02 \mathrm{~b}$ & $1.24 \pm 0.02 \mathrm{ab}$ & $1.26 \pm 0.02 \mathrm{a}$ & $1.22 \pm 0.01 \mathrm{ab}$ \\
$\mathrm{WBC}\left(\times 10^{3} / \mu \mathrm{l}\right)$ & $4.70 \pm 0.20$ & $4.90 \pm 0.30$ & $5.00 \pm 0.30$ & $4.83 \pm 0.25$ \\
$\mathrm{Hct}(\%)$ & $22.33 \pm 1.52$ & $24.00 \pm 2.00$ & $24.66 \pm 2.08$ & $23.00 \pm 2.00$ \\
$\mathrm{Hb}(\mathrm{g} / \mathrm{dl})$ & $5.90 \pm 0.10 \mathrm{~b}$ & $6.10 \pm 0.10 \mathrm{ab}$ & $6.23 \pm 0.15 \mathrm{a}$ & $5.93 \pm 0.15 \mathrm{~b}$ \\
$\mathrm{MCHC}(\mathrm{g} / \mathrm{dl})$ & $26.51 \pm 2.07$ & $25.54 \pm 2.33$ & $25.41 \pm 2.64$ & $25.96 \pm 2.96$ \\
$\mathrm{MCH}(\mathrm{pg} / \mathrm{cell})$ & $48.49 \pm 0.62$ & $49.20 \pm 1.39$ & $49.47 \pm 0.91$ & $48.49 \pm 0.64$ \\
$\mathrm{MCV}\left(\mathrm{nm}{ }^{3}\right)$ & $183.58 \pm 12.83$ & $193.66 \pm 17.73$ & $195.84 \pm 17.41$ & $188.16 \pm 18.63$ \\
\hline
\end{tabular}

Data represented as mean $\pm \mathrm{SD}$. Different letters $(\mathrm{a}-\mathrm{b})$ in the same row indicate significant differences $(\mathrm{P}<0.05)$.

Table 4. Biochemical and immunological indices of rainbow trout fed different levels of dietary inulin for 60 days $(n=30)$

\begin{tabular}{lccccc}
\hline \multicolumn{1}{c}{ Parameters } & Control & \multicolumn{1}{c|}{ T1 } & T2 & T3 \\
\hline Total Protein $(\mathrm{g} / \mathrm{L})$ & $4.19 \pm 1.49$ & $4.92 \pm 1.2$ & $5.67 \pm 1.37$ & $4.84 \pm 1.53$ \\
Albumin $(\mathrm{g} / \mathrm{L})$ & $1.03 \pm 0.34$ & $1.04 \pm 0.13$ & $1.09 \pm 0.02$ & $1.11 \pm 0.1$ \\
Globulin $(\mathrm{g} / \mathrm{L})$ & $1.25 \pm 0.27$ & $1.18 \pm 0.25$ & $1.22 \pm 0.38$ & $1.24 \pm 0.23$ \\
Triglyceride $(\mathrm{mg} / \mathrm{dL})$ & $198.3 \pm 2.15 \mathrm{a}$ & $187.56 \pm 2.59 \mathrm{~b}$ & $189.72 \pm 3.13 \mathrm{~b}$ & $188.81 \pm 1.74 \mathrm{~b}$ \\
Cholesterol $(\mathrm{mg} / \mathrm{dL})$ & $148.79 \pm 3.23$ & $153.61 \pm 3.39$ & $149.8 \pm 3.58$ & $148.4 \pm 2.93$ \\
Glucose $(\mathrm{mg} / \mathrm{dL})$ & $40.26 \pm 1.76$ & $41.49 \pm 1.98$ & $40.84 \pm 1.59$ & $41.55 \pm 0.9$ \\
Cortisol $(\mathrm{nmol} / \mathrm{L})$ & $19.15 \pm 1.31 \mathrm{~b}$ & $20.58 \pm 1.92 \mathrm{ab}$ & $22.6 \pm 0.94 \mathrm{a}$ & $20.81 \pm 0.8 \mathrm{ab}$ \\
Total $\mathrm{Ig}(\mathrm{mg} / \mathrm{ml})$ & $11.57 \pm 1.00$ & $13.07 \pm 1.68$ & $13.38 \pm 0.95$ & $13.13 \pm 1.33$ \\
Lysozyme $(\mathrm{U} / \mathrm{ml})$ & $31.56 \pm 2.37 \mathrm{~b}$ & $34.59 \pm 0.89 \mathrm{ab}$ & $35.43 \pm 1.39 \mathrm{a}$ & $34.12 \pm 1.41 \mathrm{ab}$ \\
ACH50 $(\mathrm{U} / \mathrm{ml})$ & $23.65 \pm 1.41 \mathrm{~b}$ & $25.05 \pm 1.33 \mathrm{ab}$ & $26.80 \pm 1.18 \mathrm{a}$ & $23.96 \pm 1.31 \mathrm{~b}$ \\
\hline
\end{tabular}

Data represent as mean $\pm \mathrm{SD}$. Different letters $(\mathrm{a}-\mathrm{b})$ in the same row indicate significant differences $(\mathrm{P}<0.05)$.

Significant differences in the immune parameters of lysozyme and ACH50 were present in the $\mathrm{T} 2$ treatment compared to the control $(\mathrm{P}<0.05)$; however, no significant differences were observed in total Ig levels among treatments $(\mathrm{P}>0.05$; Table 4$)$.

\section{Mucosal immunological indices}

The immunological parameters of mucus were significantly influenced by inulin incorporation, except for ACH50 ( $\mathrm{P}<0.05$; Figures 1-5). The results indicated that the $2 \%$ incorporation of inulin produced higher values of lysozyme, ALP and protease activities, and total Ig $(\mathrm{P}<0.05$; Figure $1-4)$.

\section{Survival rates of fish challenged with $A$. hydrophila}

The survival rate percentages of fish challenged with $A$. hydrophila are presented in Figure 6. The results demonstrated that the inulin supplemented groups recorded higher levels of survival than the non-treated control group. Specifically, the $2 \%$ inulin treatment exhibited the highest survival rates in fish challenged with $A$. hydrophila up to $81 \%$ on the 14 th day, while only a $50 \%$ survival rate was observed in the control group $(\mathrm{P}<0.05)$. 


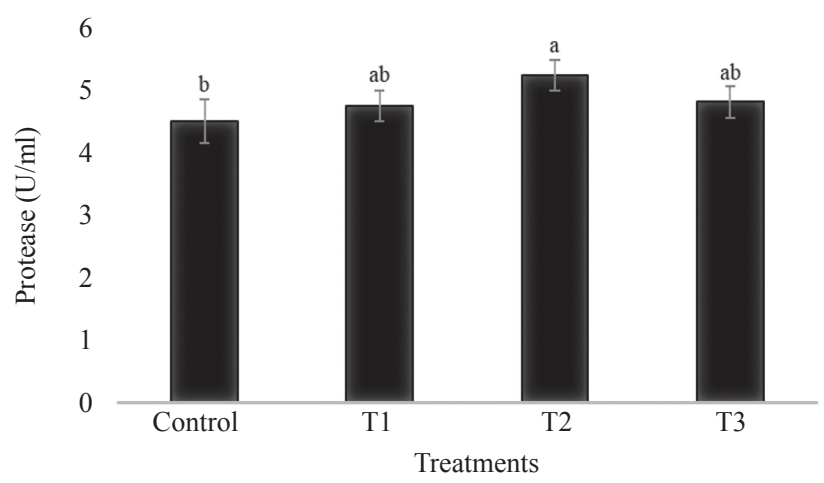

Figure 1. Effects of dietary inulin on skin mucus protease activity in rainbow trout after 60 days. Bars assigned with same superscripts are not significantly different $(\mathrm{P}>0.05)$; values are presented as mean $\pm \mathrm{SD}(\mathrm{n}=30)$

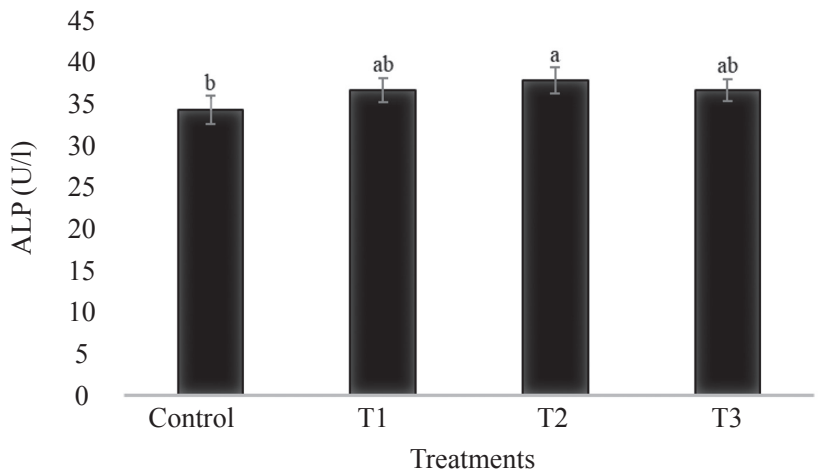

Figure 2. The effects of dietary inulin on skin mucus ALP activity in rainbow trout after 60 days. Bars assigned different superscripts are significantly different $(\mathrm{P}<0.05)$; values are presented as mean $\pm \mathrm{SD}$ $(\mathrm{n}=30)$

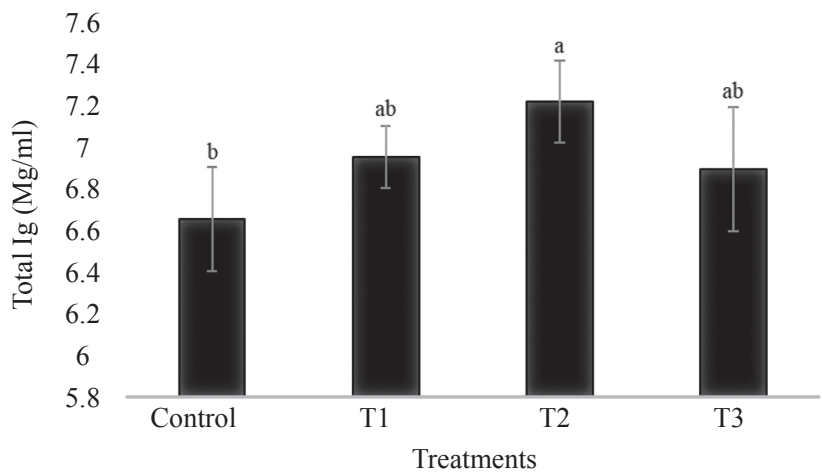

Figure 3. The effects of dietary inulin on skin mucus total immunoglobulin level in rainbow trout after 60 days. Bars assigned different superscripts are significantly different $(\mathrm{P}<0.05)$; values are presented as mean $\pm \operatorname{SD}(\mathrm{n}=30)$ 


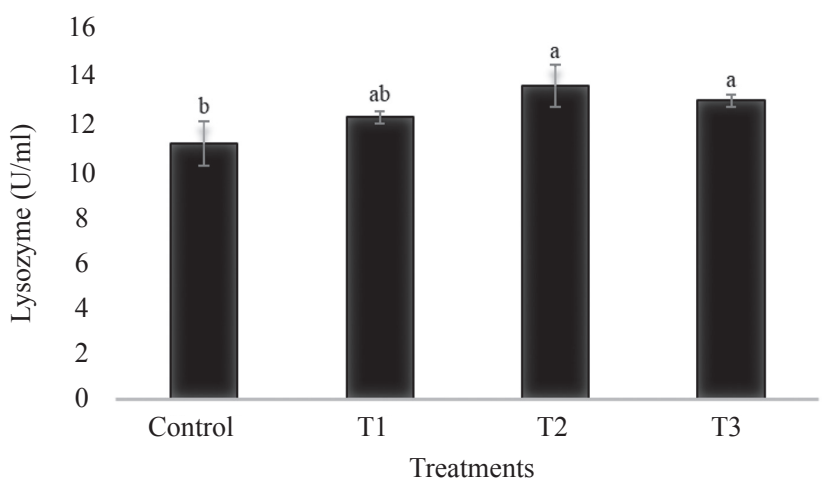

Figure 4. The effects of dietary inulin on skin mucus lysozyme activity in rainbow trout after 60 days. Bars assigned different superscripts are significantly different $(\mathrm{P}<0.05)$; values are presented as mean $\pm \mathrm{SD}(\mathrm{n}=30)$

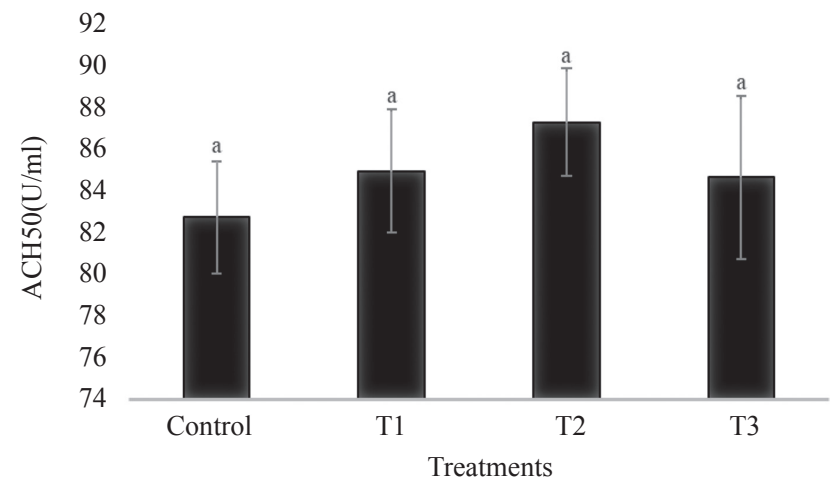

Figure 5. The effects of dietary inulin on skin mucus alternative hemolytic complement activity $(\mathrm{ACH} 50)$ in rainbow trout after 60 days. Bars assigned different superscripts are significantly different $(\mathrm{P}<0.05)$; values are presented as mean $\pm \mathrm{SD}(\mathrm{n}=30)$

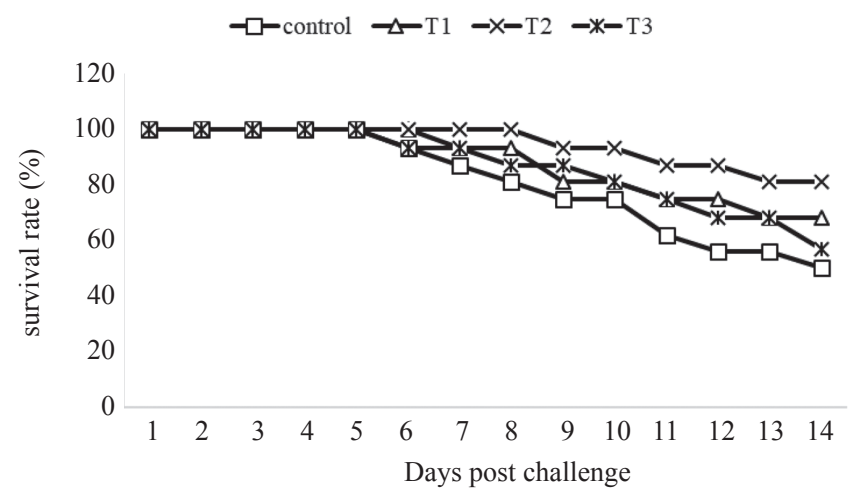

Figure 6. Survival rates of fry rainbow trout fed different levels of dietary inulin supplements (and the control) after 14 days of exposure to Aeromonas hydrophila 


\section{Discussion}

The results indicate that dietary inulin administration improves growth performance, final weight, WG, SGR, and FCR, and several hemato-immunological and serum enzyme responses. Stress tolerance reinforcement and survival rates of juvenile rainbow trout also improved after infection with $A$. hydrophila.

Several studies reported positive effects of dietary inulin in different species consistent with our results (Mahious et al., 2006; Bakke-McKellep et al., 2007; Cerezuela et al., 2008; Ibrahem et al., 2010; Burr et al., 2010; Partida-Arangure et al., 2013; Ortiz et al., 2013; Syed Raffic et al., 2016). Khosravi et al. (2010) reported improved growth performance and feed utilization in Rutilus caspicus due to dietary inulin inclusions (0.5 and 1\%). Contrastingly, Akrami et al. (2009 a, b, 2011) reported no significant effects of dietary inulin on the growth or survival rates of juvenile rainbow trout and Beluga. Similarly, Akrami et al. (2009 a, b, 2011) and Eshaghzadeh et al. (2015) found no significant improvement with dietary inulin supplementation on growth performance or feed uptake in common carp. These findings suggest that inulin may not always be an appropriate supplementation in all aquatic animal diets (Yarahmadi et al., 2016). These adverse effects of inulin inclusion on growth performance may be related to enterocyte impairment, due to the accumulation of unfermented prebiotics in the intestine, as a result of the limited ability of intestinal microbiota to ferment the given amounts of inulin (Amani Denji et al., 2015). Our results stressed the importance of prebiotic inulin supplementation in lower amounts $(2 \%)$, which proved effective in improving growth and feed utilization in rainbow trout fingerlings.

As hematological parameters are influenced by several conditions, including nutrition, environmental stress, and infection, they can be used as bio-indicators to evaluate an organism's immunological and physiological conditions (Yarahmadi et al., 2014 b). In the present study, RBC and $\mathrm{Hb}$ levels significantly increased in the $\mathrm{T} 2$ treatment compared to the other treatments. Reductions in $\mathrm{RBC}$ and $\mathrm{Hb}$ generally occur as a result of infections, and may also be symptoms of anemia, due to RBC cell destruction (Yarahmadi et al., 2016). In many studies, elevated WBC resulted from the invasion of pathogens, which reflect an organism's general health. In this study, a $2 \%$ inulin inclusion produced the highest WBC, though not significant, representing an improved immune function (Barclay et al., 2016; Kozłowska et al., 2016). Improved results were also demonstrated in all tested hematological parameters within the T2 group.

Past inulin supplements have produced varied effects on whole-body compositions, in which rainbow trout were affected by inulin dietary inclusions (Barclay et al., 2016; Kozłowska et al., 2016), whereas Lates calcarifer (Syed Raffic et al., 2016) and Oncorhynchus mykiss (Ortiz et al., 2013) were not. In our study, protein contents resulting from the inulin treatments were significantly higher than those of the control group; however, lipid, moisture, and ash contents of the inulin inclusion groups were significantly lower than the control. Similarly, Syed Raffic et al. (2016) observed the significant effects of dietary inulin on the protein contents of Asian sea bass, which did not affect lipid or ash contents. Because whole-body composition is attributed to several factors; such as life stage, species, and feeding (Mumba and 
Jose, 2005), it can be used as a fish quality indicator, reflecting its level of nutrition. Ringø et al., 2010; determined that diet ingredients and nutritional values influence the effectiveness of supplemented prebiotics of fish in different rearing conditions.

Lysozyme is a determinate factor in a fish's innate immune system, and actively plays a bactericidal role against Gram-positive and Gram-negative bacteria, and other pathogens (Saurabh and Sahoo, 2008). Serum lysozyme activity of rainbow trout was significantly elevated by dietary inulin supplementation, whereas no significant reductions in total $\mathrm{Ig}$ activities were observed. Similar results in rainbow trout fed MOS (mannan oligosaccharide) $\left(2 \mathrm{~g} \mathrm{~kg}^{-1}\right)$ reported lysozyme activity improvement (Staykov et al., 2007). He et al. (2003) observed that feeding MOS supplements to hybrid tilapia induced lysozyme and alternative complement pathway activities (ACH50). Any different or irregular findings may be the result of several factors: species type; size; age; adaptation period; culture system hygiene; feeding behavior; physiologic characteristics; quality and quantity of primary diet materials; diet formulation; type, dosage, and purity of the prebiotic; and incorporation method.

Tests involving mucus immune response revealed that fish fed $2 \%$ inulin produced significantly higher skin mucus lysozyme and protease activity, as well as total Ig and ALP levels compared to those of the other treatments and the control groups, although the effect on complement activity (ACH50) was not noticeable. Meyer (2008) revealed within fish defense mechanisms against pathogens, the innate immune system efficiency is greater than that of the adaptive immune system. Staykov et al. (2007) further noted enhanced antibody titration and lysozyme action in rainbow trout fed a MOS-supplemented diet $(0.2 \% \mathrm{w} / \mathrm{w})$. Torrecillas et al. (2007) also demonstrated high levels of macrophage phagocytic activity of the head kidney in European sea bass (Dicentrarchus labrax) fed a MOS-supplemented diet (4\%). In addition to the positive effects of supplements conferred on fish immune systems, they have also been found to prevent nonspecific immunity from definite responses (Meyer, 2008). For example, a feeding trial with MOS supplements in the diet of channel catfish (Ictalurus punctatus) produced no apparent growth improvement or improved immunity function (Welker et al., 2007). These contradictory results may be related to the suitable receptors on rainbow trout immune cells, as evidenced by the improvements observed in the non-specific immune parameters, lysozyme, and ACH50. The resumed adjuvant activity of insoluble inulin ( $\gamma$-inulin) has been suggested to activate alternative complement pathways (Silva et al., 2004). The stimulation of the alternative complement pathway through foreign bacteria was characterized as an important defense mechanism in fish (Holland and Lambris, 2002). Additionally, researchers reported the combination and expansion of specific lectin-like receptors on leucocytes and subsequent macrophage as a consequence of immune system induction with long-chained inulin (Causey et al., 1998; Seifert and Watzl, 2007; Meyer, 2008). Cerezuela et al. (2008) claimed that gilthead sea bream had no receptors on white cells capable of binding to inulin; therefore, inulin is an unsuitable choice as an immuno-stimulant for every fish type.

Our findings presented significant alterations in serum biochemical parameters through the inclusion of $2 \%$ inulin administration. Serum triglyceride and cortisol circulation were significantly higher in the fish fed inulin. The present results are in 
agreement with previous studies on the effects of dietary non-starch polysaccharides (non-digestible but fermentable oligosaccharide) on serum biochemical parameters. In contrast to our findings, Hoseinifar et al. (2011) reported cholesterol level reductions after the inclusion of oligofructose to the diets of juvenile beluga (Huso huso). The reduction of free cholesterol and triglyceride levels, as a result of feeding fish and other non-ruminant animals with non-starch polysaccharides (NSPs), has also been demonstrated (Trautwein et al., 1998; Hossain et al., 2003; Leenhouwers et al., 2007). Inulin, another type of NSP, did not significantly affect the circulating cholesterol in Oncorhynchus mykiss and Huso huso (Akrami et al., 2009 a, 2011). However, in his present study, cortisol levels were highest in the $2 \%$ inulin inclusion group. Contrary to our findings, Amirkolaie et al. (2013, 2015) reported no noticeable changes in circulating cortisol levels after the addition of $1-2 \%$ Immunogen $^{\circledR}$ in rainbow trout diets, yet did not significantly affect growth improvement and feed efficiency.

Serum total protein is one of the humoral innate immune parameters in fish that is induced by immunostimulants (Siwicki et al., 1994). Major serum proteins within the immunity system include albumin and globulin, which projects a fish's health and immunity status (Kumar et al., 2011; Tahmasebi-Kohyani et al., 2012). Where fish fed inulin presented no significant effects on serum albumin and globulin, rainbow trout fed a dietary symbiotic (Biomin IMBO) revealed elevated levels of serum total proteins (Mehrabi et al., 2012).

Our results revealed significant improvements in skin mucus immune parameters (lysozyme, ALP, protease, and total Ig) in rainbow trout fed $2 \%$ inulin over the $1 \%$, $3 \%$, and control groups. In agreement with these results, the administration of $2 \%$ GOS in a rainbow trout diet significantly increased skin mucus immune response (Hoseinifar et al., 2015). Additionally, the administration of the prebiotic xylooligosaccharide in Caspian white fish ( $R$. frisii kutum) showed several beneficial effects on skin mucus immune parameters, which can be attributed to improved immune response following the dietary administration of inulin. However, despite these beneficial results, the involved mechanisms which affect skin mucus immune responses are unknown and merit further research.

\section{Conclusion}

The results presented herein reveal that dietary inulin as a prebiotic supplementation improves growth performance and body composition of rainbow trout, as well as skin mucus and innate immune responses and biochemical parameters. Furthermore, a $2 \%$ inclusion of dietary inulin was found to increase the survival rates of rainbow trout after exposure to the pathogens A. hydrophila. However, further investigation of the effects of inulin on intestine microflora and immunity-related gene expression is needed to substantiate the effectiveness of inulin within varied supplemental levels and fish species.

\section{Financial support}

The research project was funded by the Functional Food Research Center for Well-being, Chiang Mai University, Chiang Mai, Thailand. 


\section{Conflict of interest statement}

The authors state that no conflicts of interest exist.

\section{Ethical Approval}

The study was performed following the guidelines on the use of animals for scientific purposes (National Health and Medical Research Council, Australia).

\section{References}

A hmadifar E., A krami R., Ghelichi A., Z a rejabad A.M. (2011). Effects of different dietary prebiotic insulin levels on blood serum enzymes, hematologic, and biochemical parameters of great sturgeon (Huso huso) juveniles. Comp. Clin. Pathol., 20: 447-451.

Akrami R., Ghelichi A., Manuchehri H. (2009 a). Effect of dietary inulin as prebiotic on growth performance and survival of juvenile rainbow trout (Oncorhynchus mykiss). J. Mar. Sci. Technol., 4: 1-9.

A krami R., A bdolmajid H., A b b a s M., A bd ol moha m mad AK. (2009 b). Effect of dietary prebiotic inulin on growth performance, intestinal microflora, body composition, and hematological parameters of juvenile beluga, Huso huso (Linnaeus, 1758). J. World. Aquacult. Soc., 40: 771-779.

A krami R., Ghelichi A., A hmadifar E. (2011). Effect of dietary prebiotic inulin on hematological and biochemical parameters of cultured juvenile beluga (Huso huso). J. Vet. Res., 66: 131-136.

A kra mi R., Gheli c h i A., Z a r e i E. (2012). Effect of dietary supplementation of prebiotics inulin on growth, survival, lactic acid bacteria loading, and body composition of carp (Cyprinus carpio) juvenile. J. Fisheries., 5: 87-94.

A krami R., Iri Y., Rostami H.K., Mansour M.R. (2013). Effect of dietary supplementation of fructooligosaccharide (FOS) on growth performance, survival, lactobacillus bacterial population, and hemato-immunological parameters of stellate sturgeon (Acipenser stellatus) juvenile. Fish. Shellfish. Immunol., 35: 1235-1239.

Amani Denji K., Razeghi Mansour M., Akrami R., Ghobadi S., Jafarpour SA., M irbeygi S.K. (2015). Effect of dietary prebiotic mannan oligosaccharide (MOS) on growth performance, intestinal microflora, body composition, haematological, and blood serum biochemical parameters of rainbow trout (Oncorhynchus mykiss) juveniles. J. Fisheries. Aqua. Sci., 10: 255-265.

A m i r k ol a i e A.K., R o st a mi B. (2015). Effects of dietary supplementation with Immunogen ${ }^{\circledR}$ on the growth, hematology, and gut microbiota of fingerling common carp Cyprinus carpio (Linnaeus). Fish. Aqua. Sci., 18: 379-385.

A mirkola i e A.K., Karim zadeh S., M o h a m d - J a fary A. (2013). The effects of dietary supplement of Immunogen on growth performance, and visceral and hepatic somatic indices of juvenile rainbow trout, Oncorhynchus mykiss (Walbaum, 1792). Asian. Fish. Sci., 26: 232-242.

AOAC (2019). Official methods of analysis, 21st Edition, Association of Official Analytical Chemists, Washington, DC, Chapter 16, pp. 16-17.

A t $t$ i a Y.A., H a m e d R.S., E $1-\mathrm{H}$ a m id A.A., S h a h b a H.A., B o v er a F. (2015). Effect of inulin and mannanoligosaccharides in comparison to zinc-bacitracin on growth performance, nutrient digestibility, and hematological profiles of growing rabbits. Anim. Product. Sci., 55: 80-86.

B akke-McKellep A.M., Penn M.H., Salas P.M., Refstie S., Sperstad S., Landsverk T., R ing $\varnothing$ E., Krog d a h 1 Å. (2007). Effects of dietary soybean meal, inulin, and oxytetracycline on intestinal microbiota and epithelial cell stress, apoptosis, and proliferation in the teleost Atlantic salmon (Salmo salar L.). British. J. Nutr., 97: 699-713.

Barclay T., Ginic-Markovic M., Cooper P., Petrovsky N. (2016). Inulin - a versatile polysaccharide with multiple pharmaceutical and food chemical uses. J. Excipients. Food. Chem., 1: 1132.

Benfey T.J., Sutterlin A.M. (1984). The haematology of triploid landlocked Atlantic salmon, Salmo solar L. J. Fish. Biol., 24: 333-338. 
B r ow n B. (1988). Routine hematology procedures. Hematology: Principle and Procedures. 7-122.

Burr G., Hume M., Ricke S., Nisbet D., Gat lin D. (2010). In vitro and in vivo evaluation of the prebiotics GroBiotic ${ }^{\mathbb{R}}-\mathrm{A}$, inulin, mannanoligosaccharide, and galactooligosaccharide on the digestive microbiota and performance of hybrid striped bass (Morone chrysops $\times$ Morone saxatilis). Microb. Ecol., 59: 187-198.

C a be 11 o F.C. (2006). Heavy use of prophylactic antibiotics in aquaculture: a growing problem for human and animal health and the environment. Environ. Microb., 8: 1137-1144.

C a u s e y J.L., S la in J.L., Tangled B.C., Meye r P.D. (1998). Stimulation of the human immune system by inulin in vitro. Proc. Danone Conference on Probiotics and Immunity, Bonn, Germany.

Cerezuela R., Cuesta A., Meseguer J., Ángeles E.M. (2008) Effects of inulin on gilthead sea bream (Sparus aurata L.) innate immune parameters. Fish. Shellfish. Immunol., 24: $663-668$.

Cha kraborty S.B., H a n z C C. (2011). Application of phytochemicals as an immunostimulant, antipathogenic and antistress agents in finfish culture. Rev. Aquacult., 3: 103-119.

Ebrah i m i G.,O uraj i H., Kh a le s i M., S u d a gar M., B arari A.,Z a re i D ang es araki M., J a n K halili K.H. (2012). Effects of a prebiotic, Immunogen ${ }^{\circledR}$, on feed utilization, body composition, immunity and resistance to Aeromonas hydrophila infection in the common carp Cyprinus carpio (Linnaeus) fingerlings. J. Anim. Physiol. Anim. Nutr. 96: 591-599.

Eshaghzadeh H., Hos e in ifar S.H., Vahabzadeh H., Ringø E. (2015). The effects of dietary inulin on growth performances, survival, and digestive enzyme activities of common carp (Cyprinus carpio) fry. Aquacult. Nutr., 21: 242-247.

FAO (2018). The State of World Fisheries and Aquaculture: Contributing to Food Security and Nutrition for All. Italy, Rome, pp. 227.

F ars ani M.N., Hos e in if ar S.H., Rashidian G., Farsani H.G., A shouri G., Van Doa n H. (2019). Dietary effects of Coriandrum sativum extract on growth performance, physiological and innate immune responses, and resistance of rainbow trout (Oncorhynchus mykiss) against Yersinia ruckeri. Fish. Shellfish. Immunol., 91: 233-240.

Ge n c M.A., A k t a s M., G en c E., Y 11 m a z E. (2007 a). Effects of dietary mannan oligosaccharide on growth, body composition, and hepatopancreas histology of Penaeus semisulcatus (de Haan 1844). Aquacult. Nutr., 13: 156-161.

G e n c M.A., Y i $1 \mathrm{~m}$ a z E., G e n c E., A k t a s M. (2007 b). Effects of dietary mannan oligosaccharides (MOS) on growth, body composition, and intestine and liver histology of the hybrid Tilapia (Oreochromis niloticus $\times$ O. aureus). Israeli. J. Aquacult., 59: 10-16.

Gri s d a l e- H e 11 and B., He $1 \mathrm{l}$ a n d S.J., G a t 1 in D.M. (2008). The effect of dietary supplementation with mannanoligosaccharide, fructooligosaccharide, or galactooligosaccharide on the growth and feed of Atlantic salmon (Salmo salar). Aquacult., 283: 163-167.

H e S., X u G., W u Y., We n g H., X i e H. (2003). Effects of IMO and FOS on the growth performance and non-specific immunity in hybrid tilapia (in Chinese). Chinese. Feed., 23: 14-15.

Holl a n d M.C.H., L a m b r is J.D. (2002). The complement system in teleosts. Fish. Shellfish. Immunol., 12: 399-420.

Hoseini S.M., Pérez-Jiménez A., Costas B., Azeredo R., Gesto M. (2019). Physiological roles of tryptophan in teleosts: current knowledge and perspectives for future studies. Rev. Aquacult., 11: 3-24.

Hos e in i S.M., Mirghaed A.T., Gheli chpour M., Pagheh E., Iri Y., Kor A. (2020). Effects of dietary tryptophan supplementation and stocking density on growth performance and stress responses in rainbow trout (Oncorhynchus mykiss). Aquaculture, 519: 734908.

Hos e in i S.M., Mirghaed A.T., Ghelich pour M. (2020). Effects of dietary tryptophan levels and fish stocking density on immunological and antioxidant responses and bactericidal activity against Aeromonas hydrophila in rainbow trout (Oncorhynchus mykiss). Aquacult. Res., 51: 1455-1463.

Hoseinifar S.H., Mirvaghefi A., Merrifield D.L., Mojazi Amiri B., Yelghi S., Darvish Bastami K. (2011). The study of some haematological and serum biochemical parameters of juvenile beluga (Huso huso) fed oligofructose. Fish. Physiol. Biochem., 37: 91-96.

Hos e in if a r S.H., Est e ba n M.Á., C u e s t a A., S un Y.Z. (2015). Prebiotics and fish immune 
response: a review of current knowledge and future perspectives. Rev. Fisheries Sci. Aquacult., 23: $315-328$.

Hossain S., Hashimoto M., Choudhury E.K., Alam N., Hussain S., Hasan M., Choudhury S.K., Mahmud I. (2003). Dietary mushroom (Pleurotus ostreatus) ameliorates atherogenic lipid in hypercholesterolaemic rats. Clinic. Experimen. Pharmacol. Physiol., 30: $470-475$.

H u e bner J., We hling R.L., Hutk in s R.W. (2007). Functional activity of commercial prebiotics. Int. Dairy. J., 17: 770-775.

Ibrahem M.D., Fathi M., M es alhy S., A bd E 1-A ty A.D. (2010). Effect of dietary supplementation of inulin and vitamin $\mathrm{C}$ on the growth, hematology, innate immunity, and resistance of Nile tilapia (Oreochromis niloticus). Fish. Shellfish. Immunol., 29: 241-246.

Ke 11 y G. (2009). Inulin-Type Prebiotics: A Review (Part 2). Altern. Med. Rev., 14: 36-55.

Khodadadi M., Abbasi N., Adorian T.J., Fars ani H.G., Heday at i A., Hos e in i S.M. (2018). Growth performance, survival, body composition, hematological parameters, intestinal histomorphology, and digestive enzymes' activity in juvenile rainbow trout (Oncorhynchus mykiss) fed dietary Immunogen ${ }^{\circledR}$. Appl. Aquacult., 30: 174-86.

Khosravi M., Shamsaye Mehrjan M., Akrami R. (2010). The impact of different levels of inulin as prebiotic in the diet on the growth performance and body composition of roach fry (Rutilus rutilus caspicus). J. Natur. Res., 1: 98-107.

Kozłowska I., Marć - P i én k ow ska J., B ednarczyk M. (2016). Beneficial aspects of inulin supplementation as a fructooligosaccharide prebiotic in monogastric animal nutrition - a review. Ann. Anim. Sci., 16: 315-331.

K u m a r H., K a w a i T., A k ir a S. (2011). Pathogen recognition by the innate immune system. International. Rev. Immunol., 30: 16-34.

L a r s e n H.N. (1964). Comparison of various methods of hemoglobin determination on catfish blood. Prog. Fish. Cult., 26: 11-15.

Le enhouwers J.I., Ter Veld M., Verreth J.A., S chram a J.W. (2007). Digesta characteristics and performance of African catfish (Clarias gariepinus) fed cereal grains that differ in viscosity. Aquaculture, 264: 330-341.

Li J., Tan B., Mai K. (2009). Dietary probiotic Bacillus OJ and isomaltooligosaccharides influence the intestine microbial populations, immune responses, and resistance to white spot syndrome virus in shrimp (Litopenaeus vannamei). Aquaculture, 291: 35-40.

Madriga l L., S a n gron is E. (2007). Inulin and derivates as key ingredients in functional foods. Archiv. Latinoam. Nutr., 57: 387-396.

Mahious A.S., Gates oupe F.J., Hervi M., Metailler R., Ollevier F. (2006). Effect of dietary inulin and oligosaccharides as prebiotics for weaning turbot, Psetta maxima (Linnaeus, C. 1758). Aquacult. Int., 14: 219-229.

Mann ing T.S., G ib s on G.R. (2004). Prebiotics. Best. Pract. Res. Clin. Gastroenterol., 18: 287-298.

Mehrabi Z., Firouzbakhsh F., Jafarpour A. (2012). Effects of dietary supplementation of synbiotic on growth performance, serum biochemical parameters, and carcass composition in rainbow trout (Oncorhynchus mykiss) fingerlings. J. Anim. Physiol. Anim. Nutr., 96: 474-481.

M e y e r D. (2008). Prebiotic dietary fibers and the immune system. Agro. Food. Indust., 19: 12-15.

M irghaed A.T., Ho s e in i S.M., Gheli chpour M. (2018). Effects of dietary 1, 8-cineole supplementation on physiological, immunological, and antioxidant responses to crowding stress in rainbow trout (Oncorhynchus mykiss). Fish. Shellfish. Immunol., 81: 182-188.

M u m b a P.P., J o s e M. (2005). Nutrient composition of selected fresh and processed fish species from Lake Malawi: A nutritional possibility for people living with HIV/AIDS. Int. J. Cons. Studies, 29: $72-77$.

North B.P., Turnbull J.F., E1lis T., Porter M.J., Migaud H., Bron J., Brom age N.R. (2006). The impact of stocking density on the welfare of rainbow trout (Oncorhynchus mykiss). Aquaculture, 255: 466-479.

N y a E.J., A u s t i n B. (2009). Use of garlic, Allium sativum, to control Aeromonas hydrophila infection in rainbow trout, Oncorhynchus mykiss (Walbaum). J. Fish Dis., 32: 963-970.

Ortiz L.T., R e bolé A., Ve las c o S., R odríguez M.L., Treviño J., Tej e dor J.L., A 1 zu e t a C. (2013). Effects of inulin and fructooligosaccharides on growth performance, body chemical 
composition, and intestinal microbiota of farmed rainbow trout (Oncorhynchus mykiss). Aquacult. Nutr., 19: 475-482.

Ortuno J., Est e ban M.A., M u lero V., Mes e guer J. (1998). Methods for studying the hemolytic, chemoattractant, and opsonic activities of seabream (Sparus aurata L.) serum. In: Methodology in fish diseases research, Barnes A.C., Davidson G.A., Hiney M.P., Mclntosh D. (eds). Vol. I. Aberdeen Fisheries Research Services, Scotland, pp. 97-100.

P arry R.M., Ch a nd a n R.C., S h a h a n i K.M. (1965). A rapid and sensitive assay of muramidase. Proc. Society for Experimental Biology \& Medicine. Society for Experimental Biology and Medicine (New York, NY), Royal Society of Medicine, London, pp. 384-386.

Partida-Arangure B.O., Luna-González A., Fierro-Coronado J.A., del Carmen Flores-Miranda M., González-O c a m po H.A. (2013). Effect of inulin and probiotic bacteria on growth, survival, immune response, and prevalence of white spot syndrome virus (WSSV) in Litopenaeus vannamei cultured under laboratory conditions. African. J. Biotech., 12(21).

Ringø E., Olsen R., Gifstad T., Dalmo R., A m lund H., Hemre G.I., Bakke A.M. (2010). Prebiotics in aquaculture: review. Aquacult. Nutr., 16: 117-136.

Ringø E., D im itroglou A., Hos e in ifar S.H., Davies S.J. (2014). Prebiotics in finfish: an update. In: Aquaculture Nutrition: Gut Health, Probiotics, and Prebiotics, D. Merrifield, E. Ringø (eds). Wiley Online Library, pp. 360-400.

Ros s N.W., Firth K.J., Wang A., Burka J.F., Johnson S.C. (2000). Changes in hydrolytic enzyme activities of naïve Atlantic salmon Salmo salar skin mucus due to infection with the salmon louse Lepeophtheirus salmonis and cortisol implantation. Dis. Aqua. Organ., 41: 43-51.

S ah in K., Yazlak H., Orhan C., Tuzcu M., A kdemir F., S ah in N. (2014). The effect of lycopene on antioxidant status in rainbow trout (Oncorhynchus mykiss) reared under high stocking density. Aquaculture, 418: 132-138.

Salze G., McLean E., Schwarz M.H. (2008). Craig SR. Dietary mannan oligosaccharide enhances salinity tolerance and gut development of larval cobia. Aquaculture, 274: 148-152.

S a r d e r M.R.I., T h o m p s o n K.D., P e n m a n D.J., M c A n d rew B.J. (2001). Immune responses of Nile tilapia (Oreochromis niloticus L.) clones: I. Non-specific responses. Dev. Comp. Immunol., 25: $37-46$.

S a u rabh S., S a h o o P.K. (2008). Lysozyme: an important defense molecule of the fish innate immune system. Aquacult. Res., 39: 223-239.

S e if e rt S., Watzl B. (2007). Inulin and oligofructose: a review of experimental data on immune modulation. J. Nutr., 137: 2563S-2567S.

Sheikholes lami Amiri M., Yousefian M., Yavari V., S a fari R., Ghiy asi M. (2012). Evaluation of inulin as prebiotic on rainbow trout (Oncorhynchus mykiss) (Walbaum, 1972) immunity characteristics and resistance to Streptococcus sp. infection. Iranian. J. Bio., 24: 303-312.

Silva D.G., C o o per P.D., P etrovs k y N. (2004). Inulin-derived adjuvant efficiently promotes both Th1 and Th2 immune responses. Immunol. Cell. Biol., 82: 611-616.

Siwicki A., Anderson D. (2000). Nonspecific defense mechanisms assay in fish: II. Potential killing activity of neutrophils and macrophages, lysozyme activity in serum and organs and total immunoglobulin level in serum. FAO project GCP/ INT/JPA, IFI, Olsztyn, Poland, pp. 105-112.

S iw i cki A.K., A nders on D.P., Rum s e y G.L. (1994). Dietary intake of immunostimulants by rainbow trout affects non-specific immunity and protection against furunculosis. Vet. Immunol. Immunopathol., 1: 125-139.

Sole im ani N., Hos e in ifar S.H., Merrifield D.L., B arati M., A badi Z.H. (2012). Dietary supplementation of fructooligosaccharide (FOS) improves the innate immune response, stress resistance, digestive enzyme activities, and growth performance of Caspian roach (Rutilus rutilus) fry. Fish. Shellfish. Immunol., 32: 316-321.

S o n g S.K., B e c k B.R., K i m D., P a r k J., K i m J., K i m H.D., R ing ø E. (2014). Prebiotics as immunostimulants in aquaculture: a review. Fish. Shellfish. Immunol., 40: 40-48.

$\mathrm{S} ø \mathrm{r} \mathrm{u} \mathrm{m} \mathrm{H.} \mathrm{(2006).} \mathrm{Antimicrobial} \mathrm{drug} \mathrm{resistance} \mathrm{in} \mathrm{fish} \mathrm{pathogens.} \mathrm{In} \mathrm{Antimicrobial} \mathrm{resistance} \mathrm{in} \mathrm{bac-}$ teria of animal origin. Am. Soc. Microb., pp. 213-238.

S t a y k ov Y., S pring P., D e nev S., S w e e t m a n J. (2007). Effect of a mannan oligosaccharide on the growth performance and immune status of rainbow trout (Oncorhynchus mykiss). Aquacult. Int., 15: 153-161. 
Syed Raffic S., Ali Ambasankar A., Nandakumar S., Ezhil Praveena P. (2016). Effect of dietary inulin on growth, body composition, and gut microbiota on Asian sea bass (Lates calcarifer). Anim. Feed. Sci. Technol., 217: 87-94.

Tahmasebi-Kohyani A., Keyvanshokooh S., Nematollahi A., Mahmoudi N., Pasha-Zanoosi H. (2012). Effects of dietary nucleotides supplementation on rainbow trout (Oncorhynchus mykiss) performance and acute stress response. Fish. Physiol. Biochem., 38: $431-440$.

Te i t e $1 \mathrm{~b}$ a u m J.E., Wa $1 \mathrm{ke}$ e W.A. (2002). Nutritional impact of pre- and probiotics as protective gastrointestinal organisms. Annu. Rev. Nutr., 22: 107-138.

Torrecillas S., Makol A., Caballero M.J., Montero D., Robaina L., Real F., $\mathrm{S}$ we e tman J. (2007). Immune stimulation and improved infection resistance in European sea bass (Dicentrarchus labrax) fed mannan oligosaccharides. Fish. Shellfish. Immunol., 23: 969-981.

Trautwein E., Ri e c kh off D., Eebers d obler H. (1998). Dietary inulin lowers plasma cholesterol and triacylglycerol and alters bile acid profile in hamsters. J. Nutr., 128: 1937-1943.

We 1 k e r T.L., L i m C., Yild i rim-A k s o y M., Shelby R., K les i u s P.H. (2007). Immune response and resistance to stress and Edwardsiella ictaluri challenge in channel catfish, Ictalurus punctatus, fed diets containing commercial whole-cell yeast or yeast subcomponents. J. World. Aquacult. Soc., 38: 24-35.

Yan J., Gu o C., D aw o od M.A.O., G a o J. (2017). Effects of dietary chitosan on growth, lipid metabolism, immune response, and antioxidant-related gene expression in Misgurnus anguillicaudatus. Benef. Microbes., 8: 1-12.

Yarahmadi P., Farahmand H., Miandare H.K., Mirvaghefi A., Hoseinifar S.H. (2014 a). The effects of dietary Immunogen ${ }^{\mathbb{B}}$ on innate immune response, immune-related genes expression, and disease resistance of rainbow trout (Oncorhynchus mykiss). Fish. Shellfish. Immunol. 37: 209-214.

Yarahmadi P., Miandare H.K., Farahmand H., Mirvaghefi A., Hoseinifar S.H. (2014 b). Dietary fermentable fiber upregulated immune-related genes expression, increased innate immune response, and resistance of rainbow trout (Oncorhynchus mykiss) against Aeromonas hydrophila. Fish. Shellfish. Immunol., 41: 326-331.

Yarahmadi P., Farsani H.G., Khazaei A., Khodadadi M., Rashidiyan G., Jala$1 \mathrm{i}$ M.A. (2016). Protective effects of the prebiotic on the immunological indicators of rainbow trout (Oncorhynchus mykiss) infected with Aeromonas hydrophila. Fish. Shellfish. Immunol., 54: 589-597.

Yous efian M., A miri M.S. (2009). A review of the use of prebiotic in aquaculture for fish and shrimp. African. J. Biotech., 8: 7313-7318.

Z argari A., M a z a ndaran i M., H o s e in i SM. (2018). Effects of safflower (Carthamus tinctorius) extract on serum antibacterial activity of rainbow trout (Oncorhynchus mykiss) against Aeromonas hydrophila, Streptococcus iniae and Yersinia ruckeri. Int. J. Aqu. Biol., 6: 1-7.

Z h o u Z., D ing Z., Hu i y u a L.V. (2007). Effects of dietary short-chain fructooligosaccharide on intestinal microflora, survival, and growth performance of juvenile white shrimp Litopenaeusb vannamei. J. World. Aquacult. Soc., 38: 296-301.

Received: 2 V 2020

Accepted: 6 VII 2020 